\title{
Improving the Quality of Antenatal Care Using Mobile Health in Madagascar: Five-Year Cross-Sectional Study
}

Anne Caroline Benski ${ }^{1}$, MD; Nicole C Schmidt ${ }^{2}$, MD; Manuela Viviano ${ }^{3}$, MD; Giovanna Stancanelli ${ }^{4}$, MD; Adelia Soaroby ${ }^{5}$; Michael R Reich ${ }^{1,6}$, PhD

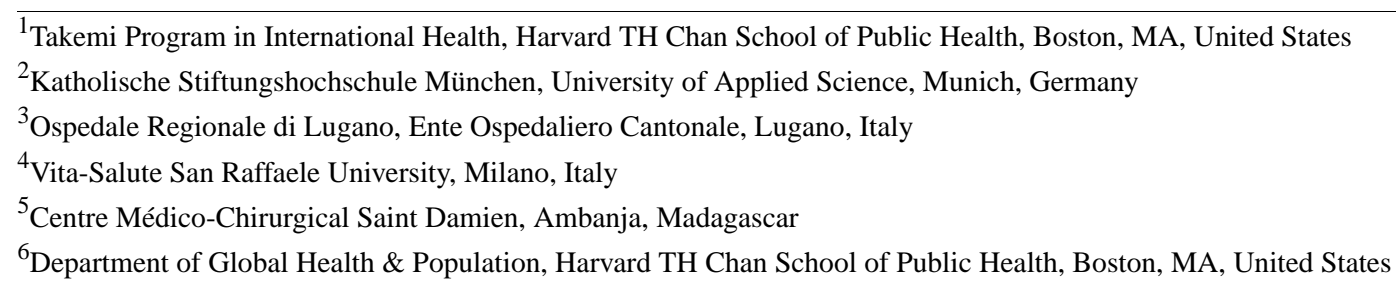

Corresponding Author:

Anne Caroline Benski, MD

Takemi Program in International Health

Harvard TH Chan School of Public Health

677 Huntington Ave

Boston, MA, 02115

United States

Phone: 1787397261

Email: cbenski@hsph.harvard.edu

\section{Abstract}

Background: Despite many efforts, maternal mortality remains a major burden in most developing countries. Mobile health (mHealth) has the potential to improve access to obstetric care through apps that help patients and providers.

Objective: This study aimed to use mHealth to provide antenatal care (ANC) to 1446 pregnant women in a rural area in Madagascar and evaluate the quality of ANC provided by an mHealth system designed to change the behaviors of providers and patients.

Methods: We included 1446 women who attended ANC visits in rural Madagascar from 2015 to 2019 using an mHealth system called Pregnancy and Newborn Diagnostic Assessment (PANDA). This cross-sectional study used data from different participants, with information collected over several years, to analyze the outputs related to the quality of ANC over time. Specifically, we examined the timing of the first ANC visit, the relationship between the visit duration and the risk factors among pregnant women, and the number of ANC visits per woman.

Results: Following the implementation of the mHealth system in 2015, we observed that women started to come earlier for their first ANC visit; more women attended their first ANC visit in the second trimester of pregnancy in 2019 than in the previous years $(P<.001)$. In 2019, fewer women attended their first ANC visit in the third trimester $(57 / 277,20.6 \%)$ than in $2015(147 / 343$, 42.9\%). There were statistically significant associations between the ANC visit durations and the risk factors, including age $(>35$ years; $25.0 \mathrm{~min}, 95 \%$ CI 24.0-25.9), educational level (longer visit for women with lower than primary education and for women who attended university and shorter for women with primary school-level education; $40.7 \mathrm{~min}, 95 \%$ CI $30.2-51.3$ and 25.3 min, $95 \%$ CI $24.4-26.3$ vs $23.3 \mathrm{~min}, 95 \%$ CI 22.9-23.8; $P=.001$ ), experience of domestic violence during pregnancy, gravidity, parity, infectious diseases (HIV, malaria, and syphilis), and level of anemia. Statistically significant associations were observed for all quality indicator variables. We observed a statistically significant increase in the number of ANC visits per woman over time from 2015 to 2017; the number of ANC visits per woman then became stable after the third year of implementing the PANDA mHealth system.

Conclusions: This study shows the potential of an mHealth system to improve the quality of ANC, change provider behavior by standardizing ANC visits, and change patient behavior by increasing the willingness to return for subsequent visits and encouraging ANC attendance early in pregnancy. As this is an exploratory study, further studies are necessary to better understand how mHealth can change behavior and identify the conditions required for behavioral changes to persist over time. 
(JMIR Mhealth Uhealth 2020;8(7):e18543) doi: 10.2196/18543

\section{KEYWORDS}

mobile health; maternal health; antenatal care; quality of care; mobile phone

\section{Introduction}

\section{Background}

Mobile health (mHealth) tools are an innovative technology that can allow patients and their health care providers to effectively access medical data before, during, and after medical appointments. mHealth has the potential to improve the quality of health care through apps that can facilitate communication between patients and health care providers [1]. In the past few decades, most health-related apps have been created for patients rather than for providers $[2,3]$.

Maternal mortality has decreased dramatically in low- and middle-income countries (LMICs), declining by $45 \%$ from 2008 to 2013 [4]; however, around the world, as many as 800 women continue to die each day because of complications from pregnancy and delivery [5]. Up to $99 \%$ of maternal deaths worldwide occur in LMICs, and researchers have postulated that a lack of access to high-quality maternal and newborn care is a major reason for maternal deaths in these countries [6,7]. Antenatal care (ANC) provides a unique opportunity for screening, diagnosis, and health promotion among pregnant women and their families and communities [8]. Appropriate utilization of ANC services is associated with improved maternal and newborn health as well as a reduction in maternal deaths during pregnancy and childbirth [9-11]. Due to the benefits of ANC, the World Health Organization (WHO) recommends that pregnant women should attend at least four ANC visits to increase opportunities for risk identification, management of pregnancy and/or comorbidities, and health promotion, and since 2016, the WHO recommends eight contacts with health care providers during pregnancy [12]. Delays in the recognition and management of clinical problems that may arise during pregnancy can increase maternal and neonatal mortality [13].

Expanded use of mHealth could help improve health care quality in the context of LMICs [14]. mHealth can offer technical support to assist health care providers in data collection and retrieval, and, even more importantly, it can support the clinical practice of health care providers and improve the quality of care and interactions between patients and health care workers [15]. If mHealth is capable of increasing patients' satisfaction with the clinical approach, this higher satisfaction may translate into increased attendance at clinical visits, which may ultimately reduce adverse obstetric and neonatal outcomes. However, current evidence on this topic is scarce, and little is known about how mHealth can influence the clinical practice of health care providers and the quality of services $[16,17]$.

\section{Objectives}

We conducted a study in Madagascar using an mHealth system to record and access women's data during their ANC visits. The main goal of this study was to evaluate the quality of ANC provided with mHealth by measuring the adherence to ANC

visits, the timing of the first ANC visit, and the duration of the visits.

\section{Methods}

\section{Study Setting and Collaboration}

This cross-sectional, observational study was conducted from January 2015 to September 2019 in the Ambanja district in northwestern Madagascar. Data related to ANC visits were collected using an mHealth system called Pregnancy and Newborn Diagnostic Assessment (PANDA). The local health authorities in Ambanja, Madagascar, and the Human Research Ethical Cantonal Board of Geneva, Switzerland (Comité d'éthique de la recherche CER 14-217; project number: CCER PB_2017-00641) approved the study.

We implemented an mHealth system to support providers in conducting ANC visits in Madagascar. Maternal mortality in Madagascar has decreased by over $50 \%$ in the last 20 years-from 776 to 353 deaths per 100,000 live births-but maternal mortality remains high and the Millennium Development Goal 5 has not been reached [18]. In the northern part of the country, $82.1 \%$ of women receive at least one ANC visit, but only $44 \%$ receive four or more ANC visits [19]. In the Ambanja district, only 58\% of pregnant women attend four or more ANC visits with any kind of health care provider [20].

The Ambanja district is a rural area with a population of 240,000 inhabitants [21]. Farming is the main economic activity in the region. This study was conducted in the 2 main hospitals in Ambanja city: the Centre Médico Chirurgical Saint Damien (a private nonprofit organization) and Centre Hospitalier de Référence du District de Ambanja (the district public hospital). In the city, ANC is provided in these 2 hospitals and in 18 dispensaries within a 200-km radius of the Ambanja district. In 2015, we provided ANC with the PANDA system in both urban and rural areas; however, in 2016, we changed the strategy and excluded rural dispensaries, providing ANC exclusively in the city of Ambanja to allow for proper follow-up.

A collaboration between the University Hospitals of Geneva and the Centre Médico Chirurgical was established in 2010 for a cervical cancer program and was continued in 2015 with the implementation of the PANDA system. The PANDA team collaborates with the Ministry of Health of Madagascar.

\section{The PANDA System Intervention}

The PANDA mHealth system was first implemented in 2015 in a pilot study to assess the system's feasibility and usability in Madagascar [22]. The program was designed to support health care providers who received training on using a smartphone app and on conducting a standardized ANC visit. This mHealth system encourages providers to perform a standardized ANC visit as the program requires the provider to go through all the sections of a standard ANC visit, without skipping any section from the beginning to the end. Standardization is an intended 
result of using an mHealth system such as PANDA. PANDA is a mobile app that facilitates the collection of information during $\mathrm{ANC}$ and postpartum care visits according to WHO recommendations. The collected data are automatically transmitted to the medical unit's web-based database, which stores a digitized medical record for each patient.

The system comprises the following 3 elements. First, PANDA point of care is a kit containing all the instruments needed to take measurements such as height, weight, body temperature, and blood pressure and to screen for syphilis, HIV, malaria, anemia, gestational diabetes, urinary tract infections, and malnutrition. Second, the PANDA app is an Android smartphone app made up of 5 sections: sociodemographic information, medical and obstetric history, clinical screening test results, health education and birth plan, and postpartum care. It is an app mostly based on icons and illustrations with very little text. A quarter of each visit is dedicated to educating the patient regarding warning signs during pregnancy, labor, and postpartum as well as birth preparedness. The education section of the visits also focuses on breastfeeding recommendations and overall well-being of women. Alert functions are integrated into the PANDA app to notify the provider of abnormal clinical results, technical problems, or missing patient information, thereby assuring a complete assessment [23]. The providers must go through all 4 modules; otherwise, it is not possible to close the visit. Third, the PANDA medical unit is a web-based database that captures the data and results collected during the ANC and postpartum visits and enables the hospital team to open a computerized medical record for each woman to make a diagnosis and define the frequency of follow-up. In addition, after all the data were collected for this study, the PANDA medical unit allowed the team to stratify pregnancies by area, time, and risk conditions. The on-site medical team has access to the PANDA database via username and password; all data are encrypted to ensure privacy. Patients were informed, and they agreed to their data being transmitted to and saved in the medical unit to create their medical records. Patients were asked to provide both paper and electronic consent.

Data were collected during the women's first and subsequent ANC visits. The 3 following types of information were collected: (1) sociodemographic characteristics; (2) medical, surgical, and obstetric history; and (3) results from screening to detect obesity or malnutrition, hypertension or preeclampsia, anemia, HIV, syphilis, malaria, diabetes, infections, and other conditions. The PANDA system collected data on at least 75 items per woman on their past and current medical and obstetric history as well as clinical screening data.

Since 2015, we have trained 13 providers to use the PANDA system. In the PANDA medical unit, it is possible to track the content of the visits, including each provider's activities, such as the number of visits conducted and eventual errors in completing the visits, thus allowing the team to build a learning curve for each provider.

\section{Sample Description}

A total of 1446 pregnant women fulfilled the inclusion criteria and were enrolled in the study. All pregnant women, regardless of age or stage of pregnancy, were eligible to participate in the study. The only exclusion criterion was the inability to understand or act as described in a previous publication explaining the acceptability and feasibility of the PANDA mHealth device [22]. As ANC with the PANDA mHealth system was offered to all women receiving routine $\mathrm{ANC}$, the sample is considered to be representative.

\section{Statistical Analysis}

We used a convenience sample of 1446 women. We planned to recruit patients from 2015 until the end of September 2020, which resulted in a total of 1446 women.

The data collected with PANDA were digitized as electronic medical records, which were used to analyze maternal morbidity and evaluate the quality of the ANC. Continuous variables are presented as mean (SD) or median, and categorical variables are presented as frequencies and relative percentages. The proportions of patients who tested positive for syphilis, HIV, or malaria are provided with their $95 \%$ CIs. Comparisons of categorical variables by year were performed using the chi-square test, and the mean durations of ANC visits were compared by the different categorical variables using the nonparametric Kruskal-Wallis test. We assessed the associations of different patient characteristics, place of residence, year, and visit order (independent variables) with visit duration (dependent variable)_first at the univariate level, using mixed linear regression models with the patient as a random factor to take into account repeated measurements within patients. We then constructed a parsimonious multivariable mixed linear regression model including all the variables that were significantly associated with the visit duration at $P=.04$. We reported the estimated marginal mean duration and $95 \% \mathrm{CI}$ for each independent variable from the multivariable model and the associated $P$ values for each category of the variables. Stata Statistical Software, release 16 (StataCorp), was used to describe the study population and to analyze the indicators of the ANC quality.

\section{Results}

\section{Demographic Information of the Participants}

Most of the 1446 women in the study were recruited in the city of Ambanja. The first table in Multimedia Appendix 1 summarizes the participants' demographic and obstetric history. The mean age of the women was 24.4 years (SD 6.8), and the majority $(1185 / 1441,82.23 \%)$ of the participants were married or living with a partner. Most of the women had primary school-level education or lower, and most (1337/1441, 92.78\%) of the participants did not have running water at home. Multiparas accounted for $60 \%$ of the participants. In our sample, more than one-third of the pregnancies were unplanned. Data on unplanned pregnancies were only included in the system in 2018 as we noticed during the visits that the women very often said that their pregnancies were not planned. In addition, data on contraceptive use before pregnancy were added in 2018 and 2019; of the women who reported previous contraceptive use in these years, $51.7 \%(170 / 329)$ used long-acting progesterone methods and $32.2 \%(106 / 329)$ used traditional methods. Only $154 / 985,15.63 \%$ of the participants had been vaccinated for tetanus. A total of $4.66 \%(67 / 1438)$ of women reported 
experiencing domestic violence during their pregnancy; importantly, several women only reported this at the end of their ANC visits, after the education session on violence.
Table 1 summarizes the status of syphilis, HIV, and malaria among the pregnant women included in this study. HIV prevalence was $1.3 \%$ (95\% CI $0.7-1.96 \%)$. The prevalence of syphilis infection in our sample was $2.8 \%$ (95\% CI 2.0-3.8\%).

Table 1. Prevalence of malaria, HIV infection, and syphilis among pregnant women in the Ambanja district, Madagascar, from January 13, 2015, to September 20, 2019, at their first antenatal care visit $(\mathrm{n}=1443)$.

\begin{tabular}{lll}
\hline Variables & Participants, $\mathrm{n}(\%)$ & $95 \%$ CI \\
\hline HIV status & & $0.7-1.96$ \\
$\quad$ Positive & $18(1.25)$ & $87.7-90.9$ \\
Negative & $1290(89.40)$ & $7.9-11.0$ \\
$\quad$ Invalid or not tested & $135(9.36)$ & $2.0-3.8$ \\
Syphilis status & & $71.2-75.8$ \\
$\quad$ Positive & $41(2.84)$ & $21.5-25.9$ \\
$\quad$ Negative & $1061(73.53)$ & $1.0-2.4$ \\
$\quad$ Invalid or not tested & $341(23.63)$ & $53.7-58.9$ \\
Malaria status & $23(1.59)$ & $39.5-44.7$ \\
$\quad$ Positive & $813(56.34)$ & \\
Negative & $607(42.06)$ & \\
$\quad$ Invalid or not tested & & \\
\hline
\end{tabular}

\section{Timing of First Antenatal Care Visit}

Table 2 shows that since the implementation of PANDA began in 2015, women tended to attend their first ANC visit earlier in their pregnancy. Comparing the timing of the first ANC visit in terms of pregnancy trimester by year, we observed a significant change from 2015 to 2019. In 2019, fewer women attended their first visit in the third trimester $(57 / 277,20.6 \%)$ than in $2015(147 / 343,42.9 \%)$. In addition, more women attended their first ANC visit in the second trimester in 2019 than in the previous years $(P<.001)$.

Table 2. Timing of the first antenatal care visit during pregnancy by year among pregnant women in the Ambanja district, Madagascar.

\begin{tabular}{lllllll}
\hline Pregnancy trimester & $\begin{array}{l}\text { Year, } \mathrm{n}(\%) \\
2015(\mathrm{n}=341)\end{array}$ & $2016(\mathrm{n}=265)$ & $2017(\mathrm{n}=197)$ & $2018(\mathrm{n}=360)$ & $2019(\mathrm{n}=276)$ \\
\hline First trimester & $28(8.2)$ & $39(14.7)$ & $28(14.2)$ & $46(12.8)$ & $18(6.5)$ & $<.001$ \\
Second trimester & $168(49.0)$ & $148(55.9)$ & $131(66.5)$ & $237(65.8)$ & $201(72.8)$ & N/A \\
Third trimester & $147(42.8)$ & $78(29.4)$ & $38(19.3)$ & $77(21.4)$ & $57(20.7)$ & N/A \\
\hline
\end{tabular}

${ }^{\mathrm{a}} \mathrm{N} / \mathrm{A}$ : not applicable.

\section{Mean Duration of Antenatal Care Visits Across Time and Associated Variables}

In the univariate analysis, the mean visit duration decreased significantly by approximately 5 min from 2015 to 2019 and varied by approximately $10 \mathrm{~min}$ across visit orders (see the second table in Multimedia Appendix 1). There was no statistically significant difference in the mean duration of the visits by the place of residence (rural vs urban). The visit duration was significantly associated with the patient's level of education, with longer visits for patients with less than primary education (mean $40.7 \mathrm{~min}$; 95\% CI 30.2-51.3 min) and patients who had completed university education (mean $25.3 \mathrm{~min} ; 95 \%$ CI 24.4-26.3 min), compared with patients who had completed primary education (mean $23.3 \mathrm{~min}$; 95\% CI 22.9-23.8 min; $P=.001$ ) or secondary school (mean $22.8 \mathrm{~min}$; 95\% CI 22.0-23.4 $\min ; P=.001)$. The visit duration also differed significantly by age, with significantly longer visits for women aged at least 35 years (mean $25.0 \mathrm{~min}$; 95\% CI 24.0-25.9 $\mathrm{min}$ ) than for those aged between 16 and 20 years (22.9 min; 95\% CI 22.3-23.5 min; $P<.001)$. Patients who reported domestic violence during the visit had longer visit durations than those who did not report domestic violence $(P<.001)$, and those who had running water at home had longer visit durations than those without running water at home. There were also significant differences in the visit duration by patient gravidity (longer duration with higher gravidity), parity (longer duration with higher parity), and trimester of pregnancy (shorter duration in the third [mean 21.7 min; 95\% CI 21.3-22.1 min; $P<.001$ ] and second [mean 25.5 min; 95\% CI 25.1-25.9 min; $P<.001]$ trimesters, compared with the first trimester [mean $29.2 \mathrm{~min}$; $95 \%$ CI $27.8-30.5 \mathrm{~min}$ ]). The providers noted that the visit duration increased with parity and gravidity as they had to go through more detailed information about each past pregnancy and delivery. Active smokers had 
longer visit durations than did nonsmokers, and women with severe or moderate anemia had longer visit durations than women with no anemia or mild anemia. Finally, there were significant differences in the visit duration by HIV status (longer duration among patients with positive HIV status compared with those with negative or unknown status), syphilis status (longer duration among patients with unknown status compared with those with positive or negative status), and malaria status (longer duration among patients with positive status compared with those with negative or unknown status). In the multivariable model, the mean visit duration remained independently associated with the year, visit order, level of education, age category, domestic violence, availability of running water at home, and HIV and syphilis status (Multimedia Appendix 1).

Figure 1 displays the mean visit duration by year and visit order. The duration of the first ANC visit remained stable over time. In 2015 and 2019, the mean duration decreased with each subsequent visit. In 2016 and 2017, the fifth visit was longer than the fourth visit, and the fourth visit was longer than the third visit in 2018.

All variables included in the multivariable model were significantly associated with the visit duration. These variables were the year, visit order, education, age, availability of running water at home, HIV status, and syphilis status.

Figure 1. Mean antenatal care visit duration in minutes (95\% CI) by year and visit order.

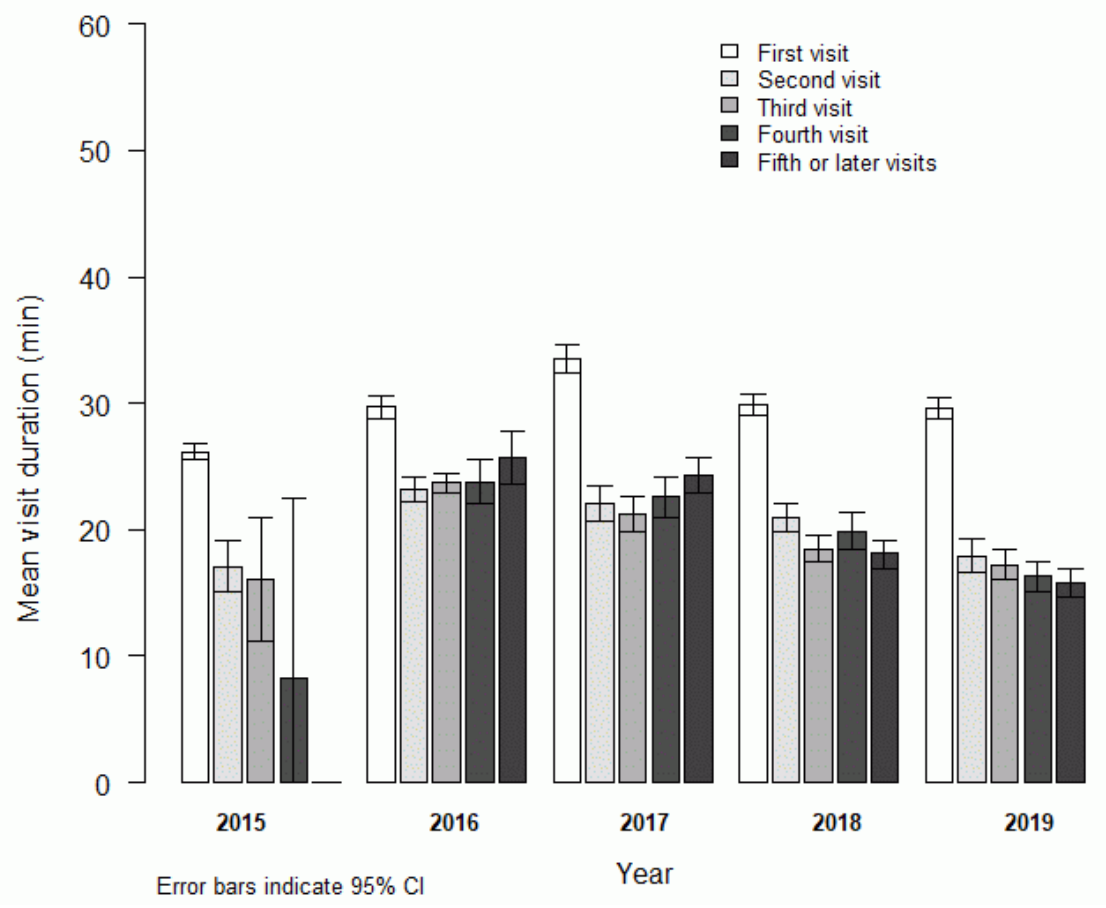

\section{Number of Visits Per Woman by Year and Antenatal Coverage}

We observed a statistically significant increase in the number of visits per woman from 2015 to 2017 . The number of visits per woman then became stable after the third year of implementing the PANDA system. Figure 2 illustrates the mean number of visits per woman per year. 
Figure 2. Mean number of antenatal care visits (95\% CI) per patient by year (Kruskal-Wallis test; $P<.001)$.

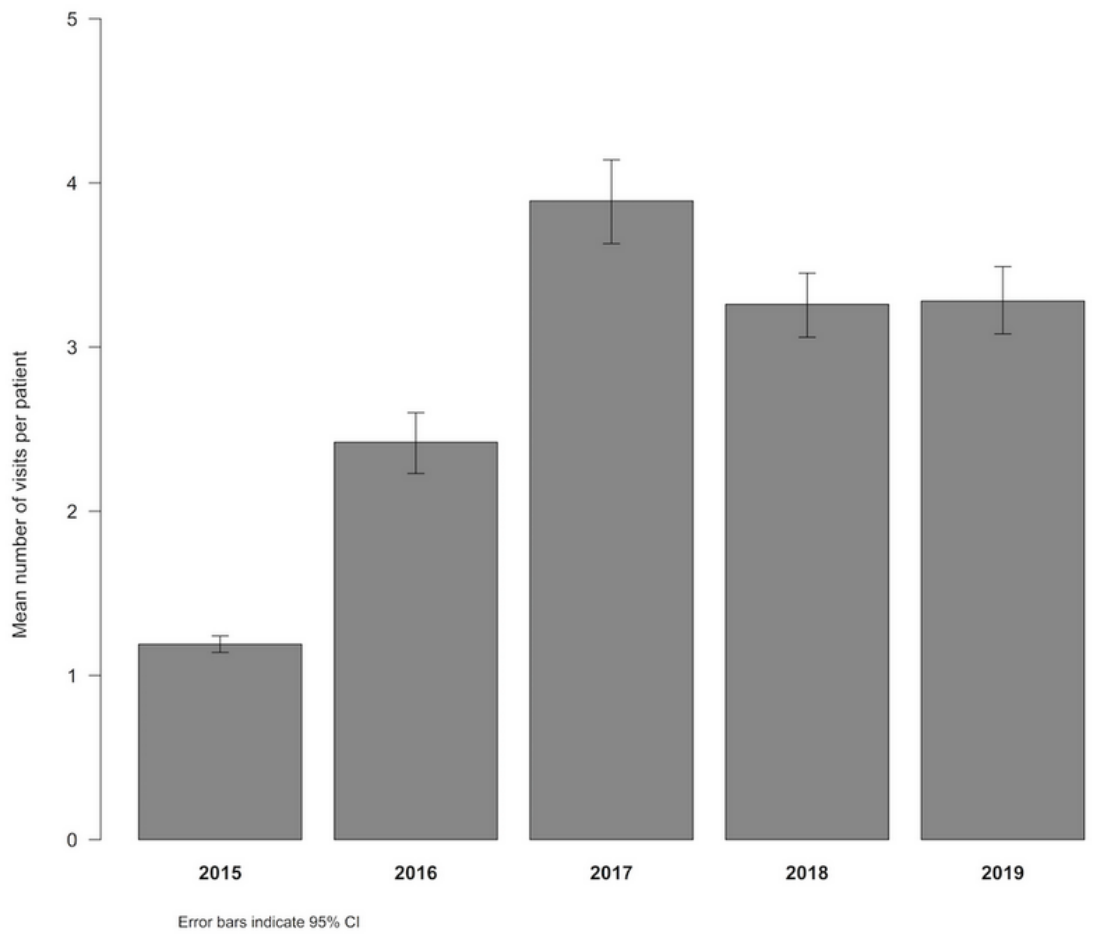

\section{Discussion}

\section{Principal Findings and Interpretation}

This study has shown the potential of using an mHealth system to encourage providers to follow a standardized ANC visit and also contribute to increase women's adherence and willingness to return for subsequent ANC visits in Ambanja, Madagascar.

According to the United Nations International Children's Emergency Fund data gathered in Madagascar in 2018, most women attended their first ANC visit in the third trimester of pregnancy, with only $45 \%$ attending their first visit in the second trimester or earlier [24]. In this study, we found that $73 \%$ of the women attended their first visit in the second trimester in 2019. This suggests that a systematically conducted ANC visit, supported and guided by mHealth technology, has the potential to boost women's confidence in health care providers. Similarly, in a randomized controlled trial conducted in 2017 in Ethiopia, Atnafu et al [25] found that, after implementing an mHealth tool to assist health care providers in collecting and organizing patient data in medical records, about $60 \%$ of the patients attended their first ANC visit from the fourth to the sixth month of their pregnancies.

There is no recommended benchmark value for the duration of ANC visits as a quality indicator; however, we assumed that a provider would need at least $20 \mathrm{~min}$ for the first ANC visit (based on our clinical experience) to cover all the main topics that should routinely be part of a high-quality ANC visit. The duration of the first ANC visit, a quality indicator defined by the WHO, remained stable over the study period, indicating that the use of the mHealth device did not significantly lengthen the visit duration. We also found that the visit duration was positively associated with several patient risk factors. Low education, being over 35 years of age, experiencing domestic violence during pregnancy, having anemia, and having an HIV positive status were all associated with a longer ANC visit duration.

In terms of the completeness of the ANC visits, most pregnant women in our sample were tested for HIV during these visits $(92.7 \%)$, compared with only $10 \%$ of pregnant women in an analysis of national-level data from 2018, which also reported that only $3 \%$ were receiving antiretroviral therapy to prevent vertical transmission [26]. Furthermore, HIV prevalence was $1.3 \%$ (95\% CI $0.7-1.96 \%)$ in our sample, compared with $0.5 \%$ (95\% CI $0.1-0.2 \%$ ) in the 2018 national-level data. The prevalence of syphilis infection in our sample was $2.8 \%$ (95\% CI 2.0-3.8\%). Previous reports of the seroprevalence of syphilis in Madagascar ranged from $1.6 \%$ to $4.5 \%$ [27]. In addition, the national-level data indicated that only $68 \%$ of pregnant women in Madagascar had their blood pressure measured during ANC visits [24], compared with almost $100 \%$ of the women in our sample using the PANDA system.

In this study, we found that the number of ANC visits per pregnant woman tended to increase over the study period. In the study by Atnafu et al, [25] the number of ANC visits varied significantly by region, with $77 \%$ of pregnant women attending 1 to 4 visits and only $23 \%$ attending more than four ANC visits. It can be assumed that increasing women's willingness to return for subsequent ANC visits may help prevent maternal morbidities that can put the mother and newborn at risk during pregnancy. Rosario et al [28] have shown that birth outcomes are directly related to ANC attendance (stillbirth: unadjusted odds ratio $[\mathrm{OR}]=0.34,95 \%$ CI $0.16-0.70$; abortion: $\mathrm{OR}=0.07$, 95\% CI 0.04-0.12) According to the national data, in 2018, only $51 \%$ of women in Madagascar attended at least four ANC visits [29]. 


\section{Strengths of the Study}

This study analyzed data from a large population over a 5-year period following the implementation of the PANDA mHealth system to support good quality ANC in a resource-constrained setting (Madagascar). The indicators in our study, such as the timing of the first ANC visit, the visit duration, and the number of visits, strongly suggest that this mHealth system encourages the performance of a standardized ANC visit and thereby facilitates the provision of high-quality ANC services. This study has shown the benefits of the PANDA mHealth system for both providers and patients. The providers received guidance on how to conduct standardized ANC of good quality, and they also received a record of all important patient data that can be used in follow-up visits. The women and their families received ongoing education and encouragement to seek appropriate care throughout the ANC and postpartum visits conducted with the PANDA system. The system improved communication between the health care workers and patients, facilitated continuous education, and encouraged the patients to play a more active role in the decision-making processes related to their health.

\section{Limitations of the Study}

Our study has several limitations. The most significant limitation is the lack of a control group to compare with participants using the PANDA mHealth system. Instead, we used national-level surveys as a standard reference-the 2009 Madagascar Demographic and Health Survey and the 2018 Multiple Indicator Cluster Survey. Although our results differed significantly from the findings of these two national-level surveys, the lack of a comparison group and a randomized design limits the conclusiveness of our findings. D-tree International's study on safer deliveries in Tanzania, which also lacked a control group, demonstrated that the examined mHealth program was a success as it reached over 13,000 pregnant women in Zanzibar. The implementation of this mHealth system was described as a success as it was linked to unprecedented rates of both service delivery and postpartum attendance, even though this mHealth system did not provide support for either ANC or postpartum visit content or quality [30]. A second limitation is that we did not measure health outcomes to evaluate the effectiveness of the mHealth intervention; we only began to collect data on postpartum visits and delivery outcomes in the last year of the study. However, the study by Lund et al [31] in Tanzania showed a trend toward improved time and quality after the implementation of a mobile phone intervention for patients in a cluster randomized control study in Tanzania. They found that the mobile phone intervention was associated with not only an increase in ANC attendance, $44 \%$ of the women in the intervention group received four or more ANC visits versus $31 \%$ in the control group ( $\mathrm{R}, 2.39$; $95 \%$ CI 1.03-5.55), but also a trend toward improved timing and quality of ANC services, although the difference was not significant. We also did not explore the cost effectiveness or durability of the PANDA system, compared with the existing paper-based checklist. These aspects need to be explored in future studies. Finally, we trained 13 providers to use the PANDA mHealth system, and we did not explore their satisfaction with the system. The providers were not selected randomly; rather, an opportunistic selection was employed.

Several questions about the use and diffusion of the PANDA mHealth system remain open. These questions relate to, for example, dealing with the low quality of service delivery and the scalable and sustainable integration of the PANDA system in the local health system.

\section{Conclusions}

This study shows that the PANDA mHealth system has the potential to improve the quality of ANC in a resource-limited setting, modify the behavior of providers by providing standardized ANC visits, and increase patient compliance. Mobile technology should not be considered a stand-alone health intervention for ANC; rather, it is a strategic tool for improving the delivery and quality of maternal health care. Further studies are necessary to better understand the conditions under which behavioral changes occur and persist over time with the use of mHealth systems such as PANDA as well as whether undesired behavioral changes may also arise with the use of mHealth in ANC settings.

\section{Acknowledgments}

The authors thank Angèle Gayet-Ageron, MD PhD MPH. for the support on the statistical analysis and Jennifer Barrett, PhD, from Edanz Group for editing the draft of this manuscript.

\section{Authors' Contributions}

$\mathrm{AB}$ participated in the study design, analysis, and writing. MR, MV, and NS took part in the revision of the paper. GS participated in the final revision of the paper.

\section{Conflicts of Interest}

None declared.

\section{Multimedia Appendix 1}

Sociodemographic and clinical characteristics of pregnant women in the Ambanja district, Madagascar, from January 13, 2015, to September 20, 2019, at their first antenatal care visit (Table 1). Sociodemographic and clinical variables that were significantly associated with antenatal care visit duration among pregnant women in the Ambanja district, Madagascar (univariate and multivariable analyses) (Table 4). 


\section{References}

1. Radin JM, Topol EJ, Steinhubl SR. A digital toolkit for improved maternal health. Lancet 2018 Sep;392(10153):1107. [doi: 10.1016/s0140-6736(18)32294-3]

2. Ilozumba O, Abejirinde IO, Dieleman M, Bardají A, Broerse JE, Van Belle S. Targeting strategies of mHealth interventions for maternal health in low and middle-income countries: a systematic review protocol. BMJ Open 2018 Feb 24;8(2):e019345 [FREE Full text] [doi: 10.1136/bmjopen-2017-019345] [Medline: 29478019]

3. Sigulem D, Ramos M, de Holanda AR. The new medicine: from the paper medical record to the digitized human being. In: Marin H, Massad E, Gutierrez MA, Rodrigues RJ, Sigulem D, editors. Global Health Informatics: How Information Technology Can Change Our Lives in a Globalized World. New York, USA: Academic Press; 2017:152-167.

4. Victora CG, Requejo JH, Barros AJ, Berman P, Bhutta Z, Boerma T, et al. Countdown to 2015: a decade of tracking progress for maternal, newborn, and child survival. Lancet 2016 May 14;387(10032):2049-2059. [doi:

10.1016/S0140-6736(15)00519-X] [Medline: 26477328]

5. World Health Organization. 2019. Maternal Mortality URL: https://www.who.int/news-room/fact-sheets/detail/ maternal-mortality [accessed 2019-11-06]

6. Kruk ME, Gage AD, Arsenault C, Jordan K, Leslie HH, Roder-DeWan S, et al. High-quality health systems in the sustainable development goals era: time for a revolution. Lancet Glob Health 2018 Nov;6(11):e1196-e1252 [FREE Full text] [doi: 10.1016/S2214-109X(18)30386-3] [Medline: $\underline{\text { 30196093] }}$

7. Campbell OM, Graham WJ, Lancet Maternal Survival Series Steering Group. Strategies for reducing maternal mortality: getting on with what works. Lancet 2006 Oct 7;368(9543):1284-1299. [doi: 10.1016/S0140-6736(06)69381-1] [Medline: 17027735]

8. Ogbo FA, Dhami MV, Ude EM, Senanayake P, Osuagwu UL, Awosemo AO, et al. Enablers and barriers to the utilization of antenatal care services in India. Int J Environ Res Public Health 2019 Aug 29;16(17) [FREE Full text] [doi: 10.3390/ijerph16173152] [Medline: $\underline{31470550]}$

9. Downe S, Finlayson K, Tunçalp O, Gülmezoglu AM. What matters to women: a systematic scoping review to identify the processes and outcomes of antenatal care provision that are important to healthy pregnant women. BJOG 2016 Mar;123(4):529-539 [FREE Full text] [doi: 10.1111/1471-0528.13819] [Medline: 26701735]

10. Blencowe H, Cousens S, Jassir F, Say L, Chou D, Mathers C, Lancet Stillbirth Epidemiology Investigator Group. National, regional, and worldwide estimates of stillbirth rates in 2015, with trends from 2000: a systematic analysis. Lancet Glob Health 2016 Mar;4(2):e98-108 [FREE Full text] [doi: 10.1016/S2214-109X(15)00275-2] [Medline: 26795602]

11. Dixit P, Khan J, Dwivedi LK, Gupta A. Dimensions of antenatal care service and the alacrity of mothers towards institutional delivery in South and South East Asia. PLoS One 2017;12(7):e0181793 [FREE Full text] [doi: 10.1371/journal.pone.0181793] [Medline: 28742809]

12. World Health Oranization. WHO Recommendations on Antenatal Care for a Positive Pregnancy Experience. Geneva, Switzerland: World Health Organization; 2016.

13. Grenier L, Suhowatsky S, Kabue MM, Noguchi LM, Mohan D, Karnad SR, et al. Impact of group antenatal care (G-ANC) versus individual antenatal care (ANC) on quality of care, ANC attendance and facility-based delivery: a pragmatic cluster-randomized controlled trial in Kenya and Nigeria. PLoS One 2019;14(10):e0222177 [FREE Full text] [doi: 10.1371/journal.pone.0222177] [Medline: 31577797]

14. Chatfield A. Maternal Health Task Force. 2014. Reflecting on the 'mHealth for Maternal Health: Bridging the Gaps' Technical Meeting URL: https://www.mhtf.org/2014/04/16/ reflecting-on-the-mhealth-for-maternal-health-bridging-the-gaps-technical-meeting/ [accessed 2020-06-09]

15. Labrique AB, Vasudevan L, Kochi E, Fabricant R, Mehl G. mHealth innovations as health system strengthening tools: 12 common applications and a visual framework. Glob Health Sci Pract 2013 Aug;1(2):160-171 [FREE Full text] [doi: 10.9745/GHSP-D-13-00031] [Medline: 25276529]

16. Chen H, Chai Y, Dong L, Niu W, Zhang P. Effectiveness and appropriateness of mhealth interventions for maternal and child health: systematic review. JMIR Mhealth Uhealth 2018 Jan 9;6(1):e7 [FREE Full text] [doi: 10.2196/mhealth.8998] [Medline: 29317380]

17. Zaidi S, Shaikh SA, Sayani S, Kazi AM, Khoja A, Hussain SS, et al. Operability, acceptability, and usefulness of a mobile app to track routine immunization performance in rural Pakistan: interview study among vaccinators and key informants. JMIR Mhealth Uhealth 2020 Mar 13;8(2):e16081 [FREE Full text] [doi: 10.2196/16081] [Medline: 32053115]

18. United Nations Economic Commission for Africa. 2013. MDG Report 2013 URL: https://www.undp.org/content/dam/ undp/library/MDG/english/MDG\%20Regional\%20Reports/Africa/MDG\%20Report2013_ENG_Fin_12June.pdf [accessed 2020-06-09]

19. Institut National de la Statistique Madagascar (INSTAT Madagascar). Institut National de la Statistique et Partenaires Techniques Financiers_Enquête Nationale sur le Suivi des Objectifs du Millénaire pour le Développement à Madagascar URL: https://www.instat.mg/wp-content/uploads/2016/11/INSTAT Ensomd Obj4-2012-2013.pdf [accessed 2019-11-10]

20. United Nations International Children's Emergency Fund (UNICEF). Antenatal Care URL: https://data.unicef.org/topic/ maternal-health/antenatal-care/ [accessed 2020-11-10] 
21. City Population. Ambanja: District in Madagascar URL: https://www.citypopulation.de/php/madagascar-admin. php?adm2id=71719 [accessed 2019-11-10]

22. Benski AC, Stancanelli G, Scaringella S, Herinainasolo JL, Jinoro J, Vassilakos P, et al. Usability and feasibility of a mobile health system to provide comprehensive antenatal care in low-income countries: PANDA mhealth pilot study in Madagascar. J Telemed Telecare 2017 Jul;23(5):536-543. [doi: 10.1177/1357633X16653540] [Medline: 27365320]

23. Salem A, Lacour O, Scaringella S, Herinianasolo J, Benski AC, Stancanelli G, et al. Cross-sectional survey of knowledge of obstetric danger signs among women in rural Madagascar. BMC Pregnancy Childbirth 2018 Feb 5;18(1):46 [FREE Full text] [doi: 10.1186/s12884-018-1664-x] [Medline: 29402226]

24. United Nations International Children's Emergency Fund (UNICEF). 2018. MICS6 Madagascar 2018 URL: https://www. unicef.org/madagascar/media/2451/file/MICS6-Madagascar-2018-Health-maternalnewborn.pdf [accessed 2020-06-09]

25. Atnafu A, Otto K, Herbst CH. The role of mhealth intervention on maternal and child health service delivery: findings from a randomized controlled field trial in rural Ethiopia. Mhealth 2017;3:39 [FREE Full text] [doi: 10.21037/mhealth.2017.08.04] [Medline: 29184891]

26. UNAIDS. Madagascar URL: https://www.unaids.org/en/regionscountries/countries/madagascar [accessed 2019-11-12]

27. Frickmann H, Schwarz N, Girmann M, Hagen R, Poppert S, Crusius S, et al. Serological survey of HIV and syphilis in pregnant women in Madagascar. Trop Med Int Health 2013 Jan;18(1):35-39 [FREE Full text] [doi: 10.1111/tmi.12007] [Medline: 23094758]

28. Rosário EV, Gomes MC, Brito M, Costa D. Determinants of maternal health care and birth outcome in the Dande health and demographic surveillance system area, Angola. PLoS One 2019;14(8):e0221280 [FREE Full text] [doi: 10.1371/journal.pone.0221280] [Medline: $\underline{\text { 31437180] }}$

29. UNFPA Madagascar,. 2013. Madagascar Millennium Development Goals National Monitoring Survey URL: https:/ /madagascar.unfpa.org/sites/default/files/pub-pdf/OMD_Summary_0.pdf [accessed 2020-06-09]

30. Battle JD, Farrow L, Tibaijuka J, Mitchell M. mHealth for safer deliveries: a mixed methods evaluation of the effect of an integrated mobile health intervention on maternal care utilization. Healthc (Amst) 2015 Dec;3(4):180-184. [doi: 10.1016/j.hjdsi.2015.10.011] [Medline: 26699340]

31. Lund S, Nielsen BB, Hemed M, Boas IM, Said A, Said K, et al. Mobile phones improve antenatal care attendance in Zanzibar: a cluster randomized controlled trial. BMC Pregnancy Childbirth 2014 Jan 17;14:29 [FREE Full text] [doi: 10.1186/1471-2393-14-29] [Medline: 24438517]

\author{
Abbreviations \\ ANC: antenatal care \\ LMIC: low- and middle-income country \\ mHealth: mobile health \\ OR: odds ratio \\ PANDA: Pregnancy and Newborn Diagnostic Assessment \\ WHO: World Health Organization
}

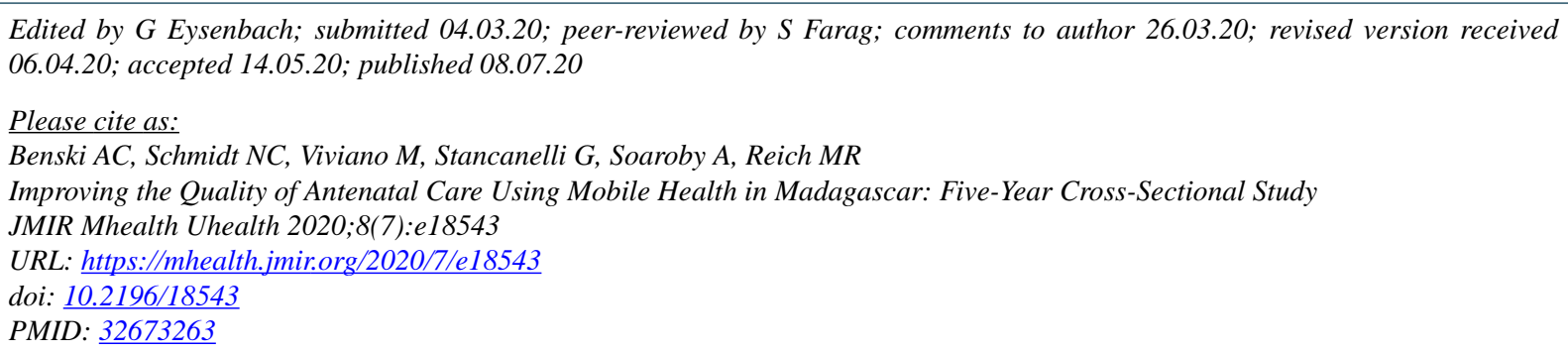

(C)Anne Caroline Benski, Nicole C Schmidt, Manuela Viviano, Giovanna Stancanelli, Adelia Soaroby, Michael R Reich. Originally published in JMIR mHealth and uHealth (http://mhealth.jmir.org), 08.07.2020. This is an open-access article distributed under the terms of the Creative Commons Attribution License (https://creativecommons.org/licenses/by/4.0/), which permits unrestricted use, distribution, and reproduction in any medium, provided the original work, first published in JMIR mHealth and uHealth, is properly cited. The complete bibliographic information, a link to the original publication on http://mhealth.jmir.org/, as well as this copyright and license information must be included. 